Running Head: OMC PREDICTIVE VALIDITY

\title{
Testing the Predictive Validity of the Open-Minded Cognition Scale
}

\author{
Jarret T. Crawford \\ The College of New Jersey
}

Mark J. Brandt

Tilburg University 


\begin{abstract}
We identify both limitations to and important omissions in predictive validity tests of the openminded cognition (OMC) scale, an indicator politically biased information processing. In five studies, we test two hypotheses derived from the conceptualization of OMC: the OMC outgroup attitude and OMC bias attenuation hypotheses. We find that whereas OMC is associated with less prejudice overall, evidence is mixed that it reduces prejudice towards attitudinally dissimilar groups, a key aspect of the OMC outgroup attitude hypothesis. We find mixed support for the OMC bias attenuation hypothesis: whereas OMC is associated with avoiding selective exposure to political information, it did not attenuate political biases across seven separate tests. We recommend further tests of the OMC scale's predictive validity before its use to assess genuine differences in cognitive style.
\end{abstract}

Keywords: personality; open-mindedness; prejudice; motivated reasoning; predictive validity 


\section{Testing the Predictive Validity of the Open-Minded Cognition Scale}

What makes some people more open to new ideas, experiences, and people, and others more closed to them? This is a question that has long interested social and personality psychologists (e.g., Rokeach, 1960). Multiple measures of cognitive styles associated with openand closed-mindedness have been developed over the years (e.g., dogmatism; Rokeach, 1960; need for cognitive closure; Kruglanski, Webster, \& Klem, 1993; openness to experience; McCrae \& Costa, 1987). Price, Ottati, Wilson, and Kim (2015) recently developed the construct and measurement of open-minded cognition (OMC) to address shortcomings in this prior work. They conceptualized OMC as ranging across domains of concern (e.g., politics, religion) and defined an open-minded cognitive style as (p. 1488):

...marked by a willingness to consider a variety of intellectual perspectives, values, attitudes, opinions, or beliefs, even those that contradict the individual's prior opinion. Open-minded individuals attend to a variety of viewpoints, consider numerous competing perspectives, and elaborate upon information in an unbiased manner...Open-minded cognition reflects a tendency to process information in a manner that is not biased in the direction of the individual's prior opinion or expectation.

In other words, people higher in OMC should be more open to a variety of people, experiences, or ideas, even those inconsistent with one’s prior beliefs. In Studies 1 - 3, Price et al. (2015) developed the general OMC scale (OMC-G) and in Study 4 they test the scales' convergent and discriminant validity. ${ }^{1}$ To demonstrate the scales’ predictive validity, Price et al. (2015) showed that OMC is associated with Empathic Concern (Study 5) and liking of seven different social groups (Blacks, Asians, Hispanics, Muslims, Transgender people, atheists, and gay people, as

\footnotetext{
${ }^{1}$ Price and colleagues (2015) also developed politics- and religion-specific versions of the scale. Because our work
} focuses on the general scale, we focus our discussion on the general scale. 
measured with 0 - 100 feeling thermometers) above and beyond other plausible correlates (e.g., openness to experience).

In our estimation, there are two primary limitations to the original attempt at assessing the OMC scale’s predictive validity. The first concerns their approach to the relationship between OMC and social group attitudes. Price et al. (2015, p. 1498) argue that OMC should be associated with "more positive emotional reactions to outgroup members.” We call this hypothesis the OMC outgroup attitudes hypothesis. However, there are two potential problems with the authors' selection of target groups in testing this hypothesis. First, the authors do not establish whether the participants are members of these groups or not; thus, it is unclear the extent to which the target groups can be considered outgroups. Second, and relatedly, the target groups are all low status or socially unconventional groups. Recent findings show that constructs typically thought to predict prejudice do not do so when more heterogeneous pools of target groups are considered (e.g., openness to experience; Brandt, Chambers, Crawford, Wetherell, \& Reyna, 2015; cognitive ability; Brandt \& Crawford, 2016; political conservatism; Crawford, Brandt, Inbar, Chambers, \& Motyl, 2017; for a review, see Crawford, 2018). Therefore, it is unclear whether OMC predicts liking of people one disagrees with (e.g., outgroups), or just liking toward low status, socially disadvantaged groups. This is especially important to consider because openness to experience (which is correlated with OMC-G, $r=.46$; Price et al., 2015, p. 1497) is associated with liking of unconventional groups, but disliking of conventional groups (Brandt et al., 2015).

The second limitation concerns what was not assessed. By definition, OMC should be associated with unbiased information processing. However, the original predictive validity tests did not assess the relationship between OMC and unbiased information processing. It is 
surprising that no such tests are reported, as this is a central quality of open-minded cognition. It is included in the above-quoted definition and highlighted elsewhere in the original report, e.g., “Open-minded cognition reflects directionally unbiased information processing. It involves a tendency to select, interpret, and elaborate upon information in a manner that is not biased toward (or against) the individual's prior opinion or expectation” (italics in original; Price et al., 2015, p. 1500). Therefore, it is essential to test the association between OMC and information processing to test the predictive validity of the OMC scale. We call this hypothesis the OMC bias attenuation hypothesis.

\section{The Present Studies ${ }^{2}$}

In light of the limitations just discussed, we conducted five studies to test the predictive validity of the OMC scale. In Studies 1a and 1b, we tested the OMC outgroup attitude hypothesis that OMC is associated with less prejudice toward a heterogeneous set of target groups, and attitudinally dissimilar groups (i.e., outgroups) in particular. If the OMC scale is a valid indicator of a "willingness to consider a variety of intellectual perspectives, values, attitudes, opinions, or beliefs, even those that contradict the individual’s prior opinion" (Price et al., 2015, p. 1488), then we would expect that OMC would not only predict less prejudice overall, but that it would especially reduce prejudice toward attitudinally dissimilar groups. Such tests are theoretically necessary to the definition of open-minded cognition, but were not adequately conducted as a part of the original set of studies.

In Studies 2a, 2b, and 3, we tested the OMC bias attenuation hypothesis that OMC should attenuate biased information processing. These studies examine this relationship across three different biased information processing paradigms. As with the OMC outgroup attitude

\footnotetext{
${ }^{2}$ JTC and MJB conceptualized the study designs. VG assisted JTC with survey material creation. JTC conducted analyses and wrote the manuscript. MJB and VG provided critical feedback on the manuscript.
} 
OMC PREDICTIVE VALIDITY 6

hypothesis, such tests are theoretically necessary to the definition of Open-minded cognition; however, these were not conducted as a part of the original set of studies.

\section{Studies 1a and 1b}

In Studies 1a and 1b, we tested the OMC outgroup attitude hypothesis. Specifically, we examined whether OMC was associated with less prejudice toward a socially and politically heterogeneous set of target groups.

We were especially interested if OMC is related to reduced prejudice against attitudinally dissimilar outgroups. There is a strong relationship between perceived attitudinal dissimilarity (i.e., worldview conflict) and prejudice (e.g., Brandt et al., 2015; Crawford et al., 2017). One of Price et al.’s (2015) key contentions is that people high in OMC are more open-minded, even toward groups and attitudes and opinions that contradict their own. There are two ways we test this hypothesis in Studies 1a and 1b. First, people who score high on OMC should have a weaker link between perceiving a group as attitudinally dissimilar and prejudice towards that group, compared to people who score low on OMC. That is, OMC should moderate the perceived attitude dissimilarity-prejudice relationship. Second, we measured the perceived ideology of each group along with the perceiver's own ideology to test whether OMC reduces the relationship between perceiver ideology and prejudice toward ideological outgroups. For instance, does OMC weaken the relationship between conservatism and prejudice toward liberal targets, more so than it does toward conservative targets? We tested these predictions in Studies 1a and 1b.

\section{Method}

\section{Participants}

We recruited 301 participants for Study 1a (58\% Male, $M_{\text {age }}=34$ years) and 602 participants for Study 1b (45\% male; $M_{\text {age }}=37$ years) through Mechanical Turk. We chose to 
use Mechanical Turk because it is similar to the samples used in Price et al.'s (2015) original research. We collected Study 1a in November 2015. Because one of the key effects was marginally significant, we collected another sample (Study 1b) in November 2017, with an increased sample size and number of target groups. These sample sizes gave us adequate power to detect medium sized effects (power $>99.9 \%$ ). Given the centrality of our tests to the conceptualization of OMC, we believe it is reasonable to expect medium sized effects.

\section{Materials and Procedures}

All data sets and survey materials ${ }^{3}$ are available on the Open Science Framework (OSF) at: https://osf.io/a5jmy/

Participants first completed the 6-item General Open-minded Cognition scale (OMC-G; Price et al., 2015; Study 1a: $M=5.06, S D=.96, \alpha=.79 ;$ Study $1 \mathrm{~b}: M=5.10 ; S D=1.02 ; \alpha=.81$ ) $(1$ = strongly disagree; 7 = strongly agree $) .{ }^{4}$

To measure prejudice, participants then completed feeling thermometer ratings $(0=$ very cold; 100 = very warm; reverse-scored) of 18 (Study 1a) and 43 (Study 1b) target groups, in random order. Targets for Study 1a were drawn from the seven groups included in Price et al. (2015) (Blacks, Asian-Americans, Latinos, Muslims, transgender people, atheists, and gays and lesbians), along with targets used in our previous studies (Republicans, Democrats, Evangelical Christians, rich people, poor people, elderly people, military personnel, business people, Whites, Southerners, supporters of the traditional family; e.g., Crawford et al., 2017). Study 1b included the above 18 targets, along with additional targets drawn from Brandt and Crawford (2016) and Koch et al. (2016) (celebrities, jocks, women, men, middle class people, working class people,

\footnotetext{
${ }^{3}$ Hypotheses derived from Price et al.’s (2015) conceptualization of OMC were not preregistered.

${ }^{4}$ In all studies, participants also completed a 14-item Openness to Experience scale (Brandt et al., 2015, Study 3) and a 20-item Need for Closure scale (NFC; Houghton \& Grewal, 2000). Scale order was randomized. We do not report these findings here because this paper is focused on OMC; however, these data are available on the OSF.
} 
homeless people, lower-class people, blue-collar workers, upper-class people, Christians, liberals, conservatives, hippies, hipsters, goths, drug addicts, teenagers, nerds, parents, Jews, politicians, religious people).

Participants then rated each group on their perceived attitudinal dissimilarity ("For each of the following groups, please indicate the extent to which you see them holding political or social beliefs different from your own;" 1 = not at all different from me; 7 = very different from me; Brandt et al., 2015; Study 1a: $M=4.22, S D=.69$; Study $1 \mathrm{~b}: M=4.14$; $S D=1.61$ ) and perceived target ideology ("For each of the following groups, please indicate how politically liberal or conservative you think they are;” 1 = very liberal; 7 = very conservative; Brandt \& Crawford, 2016; Study 1a: $M=4.23 ; S D=.41$; Study 1b: $M=3.96 ; S D=1.72$ ). ${ }^{5}$ Target order was randomized within each rating block, and the order of the rating blocks was also randomized.

Finally, participants provided demographic information (gender, age, ethnicity, religion, religiosity, education, income, SES, country of origin, political ideology, party identification).

\section{Results and Discussion}

In each study, we conducted three separate multilevel regression models using IBM SPSS 23 software. Target groups (level 1) were nested within participants (level 2) and we included random intercepts for both participants and target groups. In the first two models, we tested the key predictions of the OMC outgroup attitude hypothesis. In Model 1, we tested a) whether OMC is associated with less prejudice against all target groups (i.e., an OMC main effect), and b) whether the perceived attitudinal dissimilarity-prejudice relationship is moderated by OMC, such that the relationship is weaker for people high in OMC than for people low in OMC (i.e., an

\footnotetext{
${ }^{5}$ We also included a measure of the perceived open-mindedness of the target groups, but because it does not allow us to test the OMC outgroup attitude hypothesis, we do not report results regarding it here.
} 
OMC PREDICTIVE VALIDITY 9

OMC $\times$ attitudinal dissimilarity interaction). In Model 2, we tested whether OMC reduces the relationship between perceiver ideology and prejudice against ideologically dissimilar groups (i.e., a perceiver ideology $\times$ target ideology $\times$ OMC interaction).

\section{Testing the OMC Outgroup Attitude Hypothesis}

Study 1a, Model 1. Consistent with the idea that OMC is associated with less prejudice, there was a negative relationship between OMC and prejudice, $b=-3.71, S E=.86,95 \%$ CI [5.39, -2.02], $t=-4.33, p<.001$. Replicating previous research on worldview conflict (e.g., Brandt et al., 2014; Crawford et al., 2017), there was a main effect of perceived attitudinal dissimilarity, such that greater perceived dissimilarity was associated with greater prejudice, $b=$ 7.04, $S E=.38,95 \%$ CI $[6.28,7.79], t=18.39, p<.001$. This relationship was not moderated by OMC, $b=.63, S E=.39,95 \%$ CI $[-.15,1.40], t=1.60, p=.112$. This finding is inconsistent with the part of the OMC outgroup attitude hypothesis that people high in OMC are more open towards people with whom they disagree.

Study 1b, Model 1. Consistent with the idea that OMC is associated with less prejudice, there was a negative relationship between OMC and prejudice, $b=-4.69$, SE $=.58,95 \%$ CI [5.83, -3.54], $t=-8.05, p<.001$. There was a main effect of perceived dissimilarity, $b=5.71, S E$ $=.23,95 \%$ CI $[5.25,6.17], t=24.50, p<.001$. This relationship was not moderated by OMC, $b$ $=-.05, S E=.23,95 \%$ CI $[-.50, .40], t=-0.21, p=.834$. Again, this finding is inconsistent with the part of the OMC outgroup attitude hypothesis that people high in OMC are more open towards people with whom they disagree.

Study 1a, Model 2. Table 1 (Panel A) displays the model. The OMC $\times$ target ideology interaction was significant, as was the perceiver ideology $\times$ target ideology interaction. This latter interaction showed that liberals were more prejudiced against conservative than liberal 
groups, $b=6.89, S E=.41,95 \%$ CI [6.08, 7.69], $t=16.84, p<.001$, and conservatives were more prejudiced against liberal than conservative groups, $b=-3.28, S E=.42$, 95\% CI [-4.11, -2.46$], t$ $=-7.83, p<.001$. This interaction was qualified by a significant OMC $\times$ perceiver ideology $\times$ target ideology interaction, which is displayed in Figure 1 (top panel). Among liberals, the slopes of the OMC-prejudice relationships were equivalent across ideological ingroups, $b=-3.12, S E=$ 1.27, 95\% CI [-5.64, -.62], $t=-2.46, p=.015$, and outgroups, $b=-2.76, \mathrm{SE}=1.22,95 \% \mathrm{CI}[-$ 5.16, -.37], $t=-2.27, p=.024$. However, OMC did appear to reduce prejudice among conservatives, as the slope of the OMC-prejudice relationship among conservatives was greater toward outgroups, $b=-7.60, S E=1.40,95 \%$ CI [-10.35, -4.85$], t=-5.44, p<.001$, than it was toward ingroups, $b=-2.48, S E=1.35,95 \% \mathrm{CI}[-5.13, .17], t=-1.84, p=.066$. This finding is consistent with the OMC outgroup attitude hypothesis, but only for people who identify as political conservatives.

Study 1b, Model 2. Table 1 (Panel B) displays the model. There was a perceiver ideology $\times$ target ideology interaction, such that liberals were more prejudiced against conservative than liberal groups, $b=4.67, \mathrm{SE}=.25,95 \% \mathrm{CI}[4.17,5.16], t=18.49, p<.001$, and conservatives were more prejudiced against liberal than conservative groups, $b=-4.12, S E=.25$, 95\% CI [-4.61, -3.63], $t=-16.53, p<.001$. Unlike in Study 1b, the three-way interaction was not significant $(p=.186)$. This finding is inconsistent with the OMC outgroup attitude hypothesis.

Summary. Studies $1 \mathrm{a}$ and $1 \mathrm{~b}$ consistently showed that OMC is related to less prejudice toward a heterogeneous set of target groups. However, OMC did not weaken the dissimilarityprejudice relationship. This is inconsistent with Price et al.'s (2015) suggestion that OMC should lead people to like dissimilar others. Whereas there was evidence in Study 1a that OMC reduced prejudice toward ideological outgroups among conservatives, this finding did not extend to 
liberals and it did not replicate in Study 1b. However, because of the mixed evidence for this key interaction effect in Studies 1a and 1b, the average three-way interaction effect across the two studies was estimated using a fixed-effect meta-analysis with the metafor package (Viechtbauer, 2010) in R (R Core Team, 2017). This average effect was significantly different from zero (Meta-analytic $b=.24, S E=.07, \mathrm{z}=3.28, p=.001,95 \% \mathrm{CI}[.09, .38]$ ). Thus, there is some evidence that OMC may reduce intergroup bias among conservatives. However, there was no such effect among liberals.

Evidence for the OMC outgroup attitude hypothesis is mixed, at best. Whereas people high in OMC are generally less prejudiced than people low in OMC, they do not appear more open toward attitudinally dissimilar groups (i.e., outgroups), and there was only limited evidence of OMC reducing prejudice against ideological outgroups. The effect of OMC on outgroup prejudice is the critical argument behind Price et al.'s (2015) conceptualization of OMC as it relates to intergroup attitudes.

\section{Studies 2a and 2b}

A key reason psychologists (including Price et al., 2015) are interested in identifying people who are more (or less) open-minded is that OMC should be associated with unbiased information processing. However, no one has tested whether the OMC scale is associated with unbiased information processing, which is one of Price et al.'s (2015) key claims about OMC. In Studies $2 \mathrm{a}$ and $2 \mathrm{~b}$, we test this OMC bias attenuation hypothesis by presenting participants with scenarios known to elicit biases among different subpopulations (i.e. American liberals and conservatives), and examining whether OMC reduces the bias in each of the subpopulations. Specifically, we deployed scenarios used in research on the ideologically objectionable premise model (IOPM; Crawford, 2012), which contends that both liberals and conservatives will express 
biases when the premise of the political judgment is not objectionable to the perceiver (i.e., does not force them into a value trade-off). This research has identified a number of scenarios that elicit biases among both liberals and conservatives (Crawford, 2012; Crawford, Kay, \& Duke, 2015; Crawford \& Xhambazi, 2015). Studies 2a and 2b presented participants with such scenarios. Based on the idea that OMC reduces biases information processing, we would expect that liberals and conservatives would score higher on OMC would show less biases.

\section{Method}

\section{Participants}

We recruited 404 participants for Study 2a (47\% Male, $M_{\text {age }}=37$ years) and 405 participants for Study 2b (51\% male; $M_{\text {age }}=37$ years) through Mechanical Turk. These sample sizes give us $99.9 \%$ power to detect a medium effect.

\section{Materials and Procedure}

The key difference between studies is that participants responded to two scenarios in Study 2a and four scenarios in Study 2b. Otherwise, the procedures for these two studies were nearly identical with slight differences between the studies mentioned in Footnotes 2 and 3.

Participants first completed the OMC-G scale (Study 2a: $M=5.00 ; S D=1.02, \alpha=.83$; Study 2b: $M=5.21 ; S D=1.09, \alpha=.85$ ). They then read two (Study 2a) or four (Study 2b) different scenarios, and responded to a series of questions about each scenario $(1=$ Strongly disagree; 6 = Strongly agree .

In Study 2a, participants read about a peaceful political protest, with the target group (pro-life, pro-choice) varied between subjects. Participants completed a three-item scale ( $M=$ 2.20; $S D=1.03 ; \alpha=.80$ ) indicating their political intolerance of the protestors: "NARAL ProChoice America [National Right to Life] demonstrators should continue to be allowed to 
OMC PREDICTIVE VALIDITY 13

demonstrate” (reverse-scored); “NARAL Pro-Choice America [National Right to Life]

demonstrators should not be allowed to demonstrate;" and "Police should increase their efforts to control NARAL Pro-Choice America [National Right to Life] demonstrators.” They also read about a potential law making it legal for high school students to voluntarily pray in public schools, with the target group (Christian, Muslim) varied between subjects. Participants completed a three-item scale $(M=3.92, S D=1.56 ; \alpha=.93)$ indicating their opposition to the law: "This is a good law, and should be passed" (reverse-scored); "If I had the chance to vote on this law, I would vote against it;" and "I would vote for representatives who voted in favor of this law (reverse-scored).”

In Study 2b, participants read the same scenarios peaceful protest $(M=2.20, S D=1.11, \alpha$ $=.81)$ and voluntary prayer $(M=3.16 ; S D=1.55, \alpha=.92)$ scenarios as in Study 2a, along with two additional ones. They read an additional scenario in which the Supreme Court ruled in favor of the use of a group-based criterion in college admissions (race-based or legacy-based, varied between subjects). Participants completed a three-item scale $(M=3.26, S D=1.46, \alpha=.90)$ indicating their support for the ruling: “The Supreme Court made the right decision;” "If I were a justice on the Supreme Court, I would rule against the University’s legacy-based admissions policy” (reverse-scored); and “There are no problems with the University’s legacy-based admissions policy.” They also read a scenario in which the U.S. President is criticized by a military officer during wartime (President Trump or President Obama, varied between subjects). Participants completed a three-item scale $(M=3.00, S D=1.33, \alpha=.86)$ indicating their support for sanctioning the military officer: "The general should have been reprimanded for questioning the authority of his Commander-in-Chief;” “The general was right to question the President's 
authority” (reverse-scored); and "The general should have been forced to resign for questioning the authority of his Commander-in-Chief.”

In each study, scenario order was randomized, as was the order of items presented within each scenario. ${ }^{6}$ We then collected demographic information (gender, age, ethnicity, party identification, religion, education, income, SES, country of birth) ${ }^{7}$ along with political ideology $(1=$ very liberal; 7 = very conservative; $M=3.37, S D=1.65)$.

\section{Results and Discussion}

We used Hayes’s (2013) PROCESS macro to conducted moderated multiple regression analyses of each scenario. In Step 1, we entered participant ideology (mean-centered), OMC (mean-centered), and the dichotomous condition variable (see Tables 2 and 3 notes for variable coding values). In Step 2, we entered all two-way interactions, and entered the three-way interaction in Step 3.

In order to establish biased information processing among our participants, we should observe significant ideology $\times$ condition interactions on each scenario's outcome variable. These should be crossover interactions, such that we observe biases among liberals and conservatives, but in opposite directions (e.g., Crawford et al., 2015). For the OMC bias attenuation hypothesis, the ideology $\times$ condition interaction on each scenario’s outcome variable should be qualified by a significant three-way interaction, such that the bias effect is weaker among people high in OMC than among people low in OMC.

\section{Findings from Study 2a}

\footnotetext{
${ }^{6}$ Several additional measures were collected in Study 2a, including ratings of how objectionable each premise was perceived; feeling thermometer ratings toward each target group; and perceived ideology and worldview conflict with each group (Study $2 \mathrm{~b}$ collected feeling thermometer ratings, but no other additional measures). Analyses of these measures are beyond the scope of the present study, but the data are available on the OSF.

${ }^{7}$ Religiosity was measured in Study 2a, but not Study 2b.
} 
Peaceful protest. Table 2 (Panel A) displays the results from the model. There was a condition main effect, such that people were more politically intolerant of the pro-life group. There was also an OMC main effect, such that people high in OMC were more politically tolerant. The ideology $\times$ condition interaction was significant. Consistent with expectations, liberals (-1 SD) were more politically intolerant of the pro-life group than the pro-choice group, $b=.48, S E=.07,95 \%$ CIs [.34, .62], $t=6.77, p<.001$; however, unexpectedly, conservatives (+1 SD) were equally politically tolerant of the two groups, $b=.02$, $S E=.07$, 95\% CIs [-.11, $.15], t=.32, p=.750$. Inconsistent with the OMC bias attenuation hypothesis, the three-way interaction was not significant. No other effects were significant.

Voluntary school prayer. Table 2 (Panel B) displays the results from the model. The ideology $\times$ condition interaction was significant. Consistent with expectations, liberals more strongly favored Muslim over Christian prayer space, $b=.44, S E=.11,95 \%$ CIs [.23, .65], $t=$ 4.12, $p<.001$, whereas conservatives more strongly favored Christian over Muslim prayer space, $b=-.63, S E=.10,95 \%$ CIs [-.83, -.43$], t=-6.24, p<.001$. Inconsistent with the OMC bias attenuation hypothesis, the three-way interaction was not significant. No other effects were significant.

\section{Findings from Study $2 b$}

Peaceful protest. Table 3 (Panel A) displays the results from the model. There was an ideology main effect, such that conservatives were more politically intolerant. There was also an OMC main effect, such that people high in OMC were more politically tolerant. The ideology $\times$ condition interaction was significant. Consistent with expectations, liberals were more politically intolerant of the pro-life group than the pro-choice group, $b=.26$, $S E=.07$, 95\% CIs [.13, .39], $t$ $=3.97, p<.001$, and conservatives were marginally more politically intolerant of the pro-choice 
group than the pro-life group, $b=-.14, S E=.08,95 \%$ CIs $[-.31, .02], t=-1.69, p=.091$.

Inconsistent with the OMC bias attenuation hypothesis, the three-way interaction was not significant. No other effects were significant.

Voluntary school prayer. Table 3 (Panel B) displays the results from the model. The ideology $\times$ condition interaction was significant. Consistent with expectations, liberals more strongly favored Muslim over Christian prayer space, $b=.63$, $S E=.11,95 \%$ CIs [.42, .84], $t=$ 5.85, $p<.001$, whereas conservatives more strongly favored Christian over Muslim prayer space, $b=-.50, S E=.10,95 \%$ CIs $[-.70,-.30], t=-4.97, p<.001$. Inconsistent with the OMC bias attenuation hypothesis, the three-way interaction was not significant. No other effects were significant.

College admissions. Table 3 (Panel C) displays the results from the model. There was an ideology main effect, such that liberals were more supportive of decisions favoring group-based criteria. The ideology $\times$ condition interaction was significant. Consistent with expectations, liberals were more supportive of the race-based than legacy-based decision, $b=.44, S E=.10$, 95\% CIs [.24, .63], $t=4.43, p<.001$, whereas conservatives were more supportive of the legacybased than race-based decision, $b=-.45, S E=.10,95 \%$ CIs $[-.65,-.26], t=-4.63, p<.001$. Inconsistent with the OMC bias attenuation hypothesis, the three-way interaction was not significant. No other effects were significant.

Military officer. Table 3 (Panel D) displays the results from the model. There was a condition main effect such that people were more punitive toward the officer who criticized Obama. There was an ideology main effect, such that conservatism was associated with more punitiveness. There was also an OMC main effect, such that OMC was associated with less punitiveness. The ideology $\times$ condition interaction was significant. Consistent with expectations, 
liberals were more punitive toward the officer who criticized Obama than the one who criticized Trump, $b=.60$, $S E=.08$, 95\% CIs [.44, .77], $t=7.15, p<.001$; however, unexpectedly, conservatives were equally punitive toward the two targets, $b=-.10, S E=.10,95 \%$ CIs [-.29, .09 ], $t=-1.01, p=.314$. Inconsistent with the OMC bias attenuation hypothesis, the three-way interaction was not significant. No other effects were significant.

In all six scenarios tested, there was evidence of ideologically biased information processing, although it was not always symmetrical across ideological groups. ${ }^{8}$ That is, conditions were present to observe support for the OMC bias attenuation hypothesis. However, there was no support for this hypothesis in any of the six scenarios, as OMC did not moderate these biased information processing effects. Thus, Studies $2 \mathrm{a}$ and $2 \mathrm{~b}$ provide no support for the OMC bias attenuation hypothesis. OMC was associated with greater political tolerance (Studies 2a and $2 b$ ) and with less punitiveness (Study 2b, military officer), consistent with evidence from Studies 1a and 1b that OMC is associated with greater tolerance towards people from across the political spectrum. That said, one could argue that socially desirable responding might predict both higher levels of OMC (as OMC is correlated with Agreeableness, Price et al., 2015, a predictor of socially desirable responding, Kurtz, Tarquini, \& Iobst, 2008; further, people generally value open-mindedness; Wilson, Ottati, \& Price, 2016) as well as self-reported higher tolerance and less punitiveness.

\section{Study 3}

In Study 3, we further tested the OMC bias attenuation hypothesis by examining the role of OMC in biased assimilation and selective exposure processes. Whereas the IOPM is a more recently-developed biased information processing paradigm, biased assimilation (e.g., Lord,

${ }^{8}$ It is interesting that in these cases it was liberals who showed the most biases, contrary to popular perspectives in the field (e.g., Jost, 2017). 
Ross, \& Lepper, 1979) and selective exposure (e.g., Sears \& Freedman, 1967) are long-standing biased information processing paradigms. If OMC attenuates biased information processing, then OMC should make people more accepting of belief-inconsistent information (i.e., less evidence for biased assimilation) and to open to learning belief-inconsistent information (i.e., less evidence for selective exposure). Therefore, in Study 3, we examined whether OMC would attenuate biased assimilation, and whether OMC would predict willingness to expose oneself to belief-inconsistent information.

\section{Method}

\section{Participants}

We recruited 408 participants (52\% Male, $M_{\text {age }}=38$ years) through Mechanical Turk. This sample size gives us $99.9 \%$ power to detect a medium effect.

\section{Materials and Procedure}

Participants first completed the OMC-G scale $(M=5.05 ; S D=1.03 ; \alpha=.82)$. They then read an article that either presented an argument for or against gun control (varied between subjects). Participants then indicated how biased they believed the author of the newspaper article was ( 1 = not at all biased; 4 = somewhat biased; 7 = extremely biased $)$, and how true they thought the article was $(0=$ not at all true; $100=$ completely true; reverse-scored $)$. These items were transformed to range from 0 to 1 and combined to form an article skepticism measure $(r=$ $.38 ; M=.50 ; S D=.24)$.

Participants then completed the selective exposure task regarding the Affordable Care Act (ACA). Their prompt was, "We are interested in people's responses to a brief essay about the Affordable Care Act, also known as Obamacare. We have two essays to choose from: an essay that makes the case in favor of the Affordable Care Act, or an essay that makes the case 
against the Affordable Care Act. Please indicate which of these two brief essays you prefer to read, and you will be directed to that essay." Participants then indicated which of the two essays they preferred to read (47\% pro-ACA; 53\% anti-ACA), and were then directed to the appropriate essay.

We next assessed the same demographic information (e.g., age, gender, ethnicity) and political information (i.e., ideology, party identification) as in the previous studies. Embedded within the demographics page was an assessment of how much the participant opposes or supports seven policies, including the two issues addressed by the biased assimilation and selective exposure tasks (i.e., gun control and the ACA, respectively; 1 = strongly oppose; 7 = strongly favor $)$. We used these gun control support $(M=4.45 ; S D=2.12)$ and ACA support $(M=$ 4.17, $S D=2.14$ ) items as the independent variables for the biased assimilation and selective exposure tasks, respectively.

\section{Results and Discussion}

\section{Biased Assimilation}

We used Hayes’ (2013) PROCESS macro to conduct the moderated multiple regression analyses. We regressed article skepticism on OMC (mean-centered), gun control attitude (midpoint-centered), experimental condition (-1 = gun rights; 1 = gun control), all two-way interactions, and the three-way interaction. As in Studies 2a and 2b, basic biased information processing will be revealed by a significant crossover ideology $\times$ condition interaction. The OMC bias attenuation hypothesis is tested with the three-way interaction, such that biased assimilation should be less pronounced among people high in OMC compared to people low in OMC 
Table 4 displays the model. The gun control $\times$ condition interaction was significant. Consistent with expectations, proponents of gun control were more skeptical of the gun rights than gun control essay, $b=.11, S E=.02,95 \%$ CIs $[.08, .15], t=7.33, p<.001$, and opponents of gun control were more skeptical of the gun control than gun rights essay, $b=-.08, S E=.02,95 \%$ CIs [-.12, -.05], $t=-4.89, p<.001$. Inconsistent with the OMC bias attenuation hypothesis, the three-way interaction was not significant, with an estimate nearly perfectly centered on zero ( $b=$ $.002, S E=.01,95 \% \mathrm{CI}[-.01, .01])$. No other effects were significant.

\section{Selective Exposure}

We first created the essay choice variable (the outcome variable) based on whether participants chose an essay consistent with their prior beliefs (i.e., opposed the ACA by indicating score $<4$ on the ACA policy item and chose the anti-ACA essay, or supported the ACA by indicating score $>4$ on the policy item and chose the pro-ACA essay) or inconsistent with their prior beliefs (i.e., opposed the ACA by indicating score $<4$ on the policy item and chose the pro-ACA essay, or supported the ACA by indicating score $>4$ on the policy item and chose the anti-ACA essay). Evidence consistent with the OMC bias attenuation hypothesis would show that OMC predicts a tendency to choose a belief-inconsistent essay.

Using binary logistic regression, we regressed essay choice $(0=$ inconsistent, $1=$ consistent) on OMC (mean-centered) and ACA support (mean-centered) in Step 1, and their interaction in Step 2. Consistent with the OMC bias attenuation hypothesis, there was an OMC main effect, such that those high in OMC were more likely to choose a belief-inconsistent essay than those low in OMC, $b=-.27, S E=.12$, Wald $=5.29, p=.021$. There was also an ACA support main effect, such that ACA opponents were more likely to choose a belief-consistent essay than ACA proponents, $b=-.13, S E=.05$, Wald $=6.12, p=.013$. The interaction between 
OMC and ACA support was not significant, $b=-.002$, $S E=.05$, Wald $=.002, p=.967$, suggesting that the OMC main effect was similar for both ACA opponents and proponents.

Study 3 provided mixed support for the OMC bias attenuation hypothesis. There was no support for the hypothesis in the biased assimilation task, as OMC did not attenuate the observed biased assimilation effect. However, in the selective exposure task, people high in OMC were more willing to read a belief-inconsistent essay than people low in OMC, consistent with the OMC bias attenuation hypothesis.

\section{General Discussion}

The Open-minded cognition (OMC) scale was introduced as a measure of willingness to consider ideas, values, and beliefs inconsistent with one's own, and of unbiased information processing. Although some evidence has been previously reported supporting the discriminant validity and reliability of this measure in its initial publication (Price et al., 2016), we argued that existing evidence of its predictive validity was insufficient for two reasons.

First, the evidence in favor of what we call the OMC outgroup attitude hypothesisnamely, that OMC is associated with less prejudice, especially toward outgroups - only considered a small set of target groups (Price et al., 2015), and did not establish that participants see these groups as outgroups or dissimilar in any way. Our Studies 1a and $1 \mathrm{~b}$ tested this hypothesis by examining the relationship between OMC and prejudice toward a larger set of targets, and the effect of OMC in reducing prejudice toward outgroups. OMC was associated with less prejudice toward socially heterogeneous target groups (43 unique targets tested). This is important in itself, as several measures previously thought to relate to prejudice or tolerance (e.g., Openness to experience, cognitive ability, political conservatism) appear to only be associated with prejudice/tolerance toward particular types of groups (Brandt et al., 2015; Brandt 
\& Crawford, 2016; Crawford et al., 2017; see Crawford, 2018, for a review). However, the crucial point regarding the conceptualization of OMC is that it reduces prejudice toward outgroups (Price et al., 2015). Our data offer insufficient support for this contention. OMC did not reduce the association between perceived attitudinal dissimilarity and prejudice. That is, people high in OMC are just as prejudiced against groups they see as different from them as are people low in OMC. Evidence for the OMC outgroup attitude hypothesis was inconsistent regarding ideological outgroups. Although there was meta-analytic evidence that OMC reduced ideological outgroup prejudice among conservatives (the key interaction was significant in Study 1a, but not in Study 1b), liberals’ ideological outgroup prejudice was not reduced by OMC.

In sum, the support for the OMC outgroup attitude hypothesis is mixed at best—whereas OMC is associated with lower levels of prejudice toward an assortment of targets, there is little evidence that it reduces prejudice toward attitudinally dissimilar outgroups, the key component of the OMC construct regarding effect of OMC on intergroup attitudes (Price et al., 2015).

Second, OMC should be associated with unbiased and more open-minded information processing (Price et al., 2015), but this prediction had not been previously tested. We tested what we call the OMC bias attenuation hypothesis through three motivated reasoning paradigms: ideological objectionableness (Studies 2a and 2b), biased assimilation (Study 3), and selective exposure (Study 3). In the ideological objectionableness and biased assimilation paradigms, we successfully established politically biased information processing among our participants. However, in no case did OMC moderate these effects-people high in OMC were just as likely as those low in OMC to engage in politically biased information processing, across all seven tests of this hypothesis. 
That said, we found evidence in Study 3 that OMC is associated with willingness to consider alternative viewpoints, as OMC predicted willingness to read belief-inconsistent essays about the Affordable Care Act in the selective exposure task. Taken together, it may be that OMC does not attenuate existing biases, but that it may at least make people more open to learning about alternative beliefs or opinions. This could suggest that OMC may be associated with more openness in attitude formation (e.g., information search), but not in attitude change.

\section{Remaining Questions}

One potential question that future research could address is whether OMC would attenuate biases regarding non-political issues. It may be that political biases are particularly strong, especially in heavily partisan times (Druckman, Peterson, \& Slothus, 2013), but that OMC may be able to attenuate other types of biases. That said, given the relevance and ubiquity of political disagreement, it seems especially important to identify cognitive styles that can counteract partisan thinking, and at least based on the available evidence, OMC does not do so.

It is worth noting that open-mindedness was not associated with any particular political positions. Specifically, there were no main effects of OMC on positions on prayer in public schools (Studies 2a and 2b), using group-based information in college admissions decisions (Study 2b), or gun rights (Study 3). This is consistent with other evidence that open-minded thinking is not necessarily associated with particular positions (Kahan \& Corbin, 2016), despite the fact that OMC is associated with self-reported liberalism (Price et al., 2015). ${ }^{9}$ That said, OMC was associated with greater political tolerance of political protestors (Studies 2a and 2b), regardless of their position on abortion (Studies $2 \mathrm{a}$ and $2 \mathrm{~b}$ ), and with less punitiveness toward a military officer who criticized the President, regardless of whether that president was Bush or

\footnotetext{
${ }^{9} \mathrm{OMC}$ was significantly associated with liberalism in four of our five samples ( $r$ s between -.13 and -.25), but was unassociated with liberalism in Study 1b, $r=-.02$.
} 
Obama (Study 2b). These findings appear to support the findings from Studies $1 \mathrm{a}$ and $1 \mathrm{~b}-$ that OMC is associated with less prejudice, and more tolerance, towards groups on both sides of the political spectrum. However, it may also be that both OMC and self-reported tolerance are both associated with socially desirable responding. Future research could address this point.

\section{Recommendations}

We think that the existing evidence regarding the predictive validity of the Open-minded cognition scale suggests that it should not be used as a measure of cognitive style associated with reduced intergroup bias and unbiased information processing. There was little evidence that OMC curbs prejudice toward attitudinally dissimilar outgroups. Whereas it was associated with less prejudice toward an assortment of groups, a) the outgroup prejudice reduction is really the key component of the OMC construct regarding intergroup attitudes (Price et al., 2015), and b), it is unclear whether this OMC-prejudice main effect is simply attributable to socially desirable responding. Contrary to the construct definition, OMC was only associated with unbiased information processing in one of eight tests—a single selective exposure task. Further tests are necessary to determine whether this one significant effect is reliable. At present, what appears the most reasonable understanding of the OMC scale is that it assesses how open-minded people think that they are. It may therefore be more appropriate to consider this a measure of selfperceived open-minded cognition, rather than open-minded cognition in practice. 


\section{References}

Brandt, M. J. (2017). Predicting ideological prejudice. Psychological Science, 28, 712-722.

Brandt, M. J., Chambers, J. R., Crawford, J. T., Wetherell, G. \& Reyna, C. (2015). Bounded openness: The effect of openness to experience on intolerance is moderated by target group conventionality. Journal of Personality and Social Psychology, 109, 549-568.

Brandt, M. J., \& Crawford, J. T. (2016). Answering unresolved questions about the relationship between cognitive ability and prejudice. Social Psychological and Personality Science, 7, 884-892.

Brandt, M. J., Reyna, C., Chambers, J., Crawford, J., \& Wetherell, G. (2014). The ideologicalconflict hypothesis: Intolerance among both liberals and conservatives. Current Directions in Psychological Science, 23, 27-34.

Crawford, J.T. (2012). The ideologically objectionable premise model: Predicting biased political judgments on the left and right. Journal of Experimental Social Psychology, 48(1), 138-151.

Crawford, J. T. (2018). The politics of the psychology of prejudice. In J. T. Crawford \& L. Jussim (Eds.) Frontiers of Social Psychology Series: The Politics of SocialPsychology (pp. 99 - 115). New York: Psychology Press.

Crawford, J. T., Brandt, M. J., Inbar, Y., Chambers, J. R., \& Motyl, M. (2017). Social and economic ideologies differently predict prejudice across the political spectrum, but social issues are most divisive. Journal of Personality and Social Psychology, 112, 383- 412.

Crawford, J. T., Kay, S., \& Duke, K. E. (2015). Speaking out of both sides of their mouths: Biased political judgments within (and between) individuals. Social Psychological and Personality Science, 6, 422-430. 
Crawford, J. T., \& Xhambazi, E. (2015). Predicting political biases against the Occupy Wall Street and Tea Party movements. Political Psychology, 36, 111-121.

Druckman, J. N., Peterson, E., \& Slothus, R. (2013). How elite polarization affects public opinion formation. American Political Science Review, 107, 57-59.

Enten, H. (2017). Six months in, Trump is historically unpopular. Retrieved December 28, 2017 from: https://fivethirtyeight.com/features/six-months-in-trump-is-historically-unpopular/

Hayes, A. F. (2013). Introduction to mediation, moderation, and conditional process analysis: A regression-based approach. New York, NY: Guilford.

Houghton, D. C., \& Grewal, R. (2000). Please, let's get an answer-any answer: Need for consumer cognitive closure. Psychology \& Marketing, 17(11), 911-934.

Jost, J. T. (2017). Ideological asymmetries and the essence of political psychology. Political Psychology, 38, 167-208.

Kahan, D. M. \& Corbin, J. C. (2016). A note on the perverse effects of actively open-minded thinking on climate-change polarization. Research and Politics, 3, 1-5.

Koch, A., Imhoff, R., Dotsch, R., Unkelbach, C., \& Alves, H. (2016). The ABC of stereotypes about groups: Agency/socioeconomic success, conservative-progressive beliefs, and communion. Journal of Personality and Social Psychology, 110, 675-709.

Kurtz, J. E., Tarquini, S. J., \& Iobst, E. A. (2008). Socially desirable responding in personality assessment: Still more substance than style. Personality and Individual Differences, 45, 22-27.

Kruglanski, A. W., Webster, D. M., \& Klem, A. (1993). Motivated resistance and openness to persuasion in the presence or absence of prior information. Journal of personality and social psychology, 65, 861-861. 
Lord, C. G., Ross, L., \& Lepper, M. R. (1979). Biased assimilation and attitude polarization: The effects of prior theories on subsequently considered evidence. Journal of Personality and Social Psychology, 37, 2098-2109.

Lucas, B. J., \& Kteily, N. S. (in press). (Anti-)Egalitarianism differentially predicts empathy for members of advantaged versus disadvantaged groups. Journal of Personality and Social Psychology.

McCrae, R. R., \& Costa, P. T. (1987). Validation of the five-factor model of personality across instruments and observers. Journal of Personality and Social Psychology, 52(1), 81-90.

Price, E., Ottati, V., Wilson, C., \& Kim, S. (2015). Open-minded cognition. Personality and Social Psychology Bulletin, 41, 1488-1504.

R Core Team (2017). R: A language and environment for statistical computing. R Foundation for Statistical Computing, Vienna, Austria. URL https://www.R-project.org/.

Rokeach, M. (1960). The open and closed mind: Investigations into the nature of belief systems and personality systems. New York, NY: Basic Books.

Sears, D. O., \& Freedman, J. L. (1967). Selective exposure to information: A critical review. Public Opinion Quarterly, 31, 194-213.

Viechtbauer, W. (2010). Conducting meta-analyses in R with the metafor package. Journal of Statistical Software, 36, 1-48. URL: http://www.jstatsoft.org/v36/i03/

Wilson, C., Ottati, V., \& Price, E. (2016). Open-minded cognition: The attitude justification effect. The Journal of Positive Psychology, 12, 47-58. 
Table 1

Studies $1 a$ and $1 b$ : Does OMC moderate ideologically driven prejudice?

\begin{tabular}{lcccc}
\hline Panel A (Study 1a) & $b$ & $S E$ & $t$ & CIs \\
\hline Constant & $38.23^{* * *}$ & 1.89 & 20.18 & $34.32,42.14$ \\
OMC & $-3.99^{* * *}$ & 0.83 & -4.82 & $-5.62,-2.36$ \\
Perceiver Ideology (P) & 0.45 & 0.48 & 0.93 & $-.50,1.40$ \\
Target Ideology (T) & $1.80^{* * *}$ & 0.32 & 5.71 & $1.18,2.42$ \\
OMC $\times$ P & -.63 & 0.45 & -1.41 & $-1.51, .25$ \\
OMC $\times$ T & $.74^{* *}$ & 0.28 & 2.62 & $.19,1.30$ \\
P × T & $-3.06^{* * *}$ & 0.16 & -18.89 & $-3.38,-2.74$ \\
OMC $\times$ P $\times$ T & $.39 *$ & 0.15 & 2.61 & $.10, .68$ \\
Panel B (Study 1b) & $b$ & $S E$ & $t$ & CIs \\
\hline Constant & $38.56^{* * *}$ & 1.48 & 26.01 & $35.59,41.53$ \\
OMC & $-4.36^{* * *}$ & 0.57 & -7.66 & $-5.48,-3.24$ \\
Perceiver Ideology (P) & -0.24 & 0.35 & -0.7 & $-.93, .44$ \\
Target Ideology (T) & 0.28 & 0.19 & 1.49 & $-.09, .64$ \\
OMC $\times$ P & -0.25 & 0.32 & -0.77 & $-.88, .38$ \\
OMC $\times$ T & 0.22 & 0.17 & 1.3 & $-.11, .55$ \\
P $\times$ T & $-2.64^{* * *}$ & 0.1 & -25.99 & $-2.84,-2.44$ \\
OMC $\times$ P $\times$ T & 0.12 & 0.09 & 1.33 & $-.06, .30$ \\
\hline
\end{tabular}

${ }^{*} p<.05 ; * * p<.01 ; * * * p<.001$ 
Table 2

Study 2a: Moderated multiple regression analyses on scenario judgments

\begin{tabular}{lcccc}
\hline Peaceful protest (Panel A) & $b$ & $S E$ & $t$ & CIs \\
\hline Constant & $2.21^{* * *}$ & 0.05 & 45.74 & $2.12,2.31$ \\
Condition (C) & $.26^{* * *}$ & 0.05 & 5.33 & $.16, .36$ \\
Ideology & 0.02 & 0.03 & 0.77 & $-.04, .08$ \\
OMC & $-.35^{* * *}$ & 0.05 & -6.45 & $-.45,-.24$ \\
Ideology $\times$ C & $-.13^{* * *}$ & 0.03 & -4.29 & $-.19,-.07$ \\
Ideology $\times$ OMC & 0.001 & 0.03 & 0.04 & $-.06, .06$ \\
OMC $\times$ C & 0.01 & 0.05 & 0.25 & $-.09, .12$ \\
Ideology $\times$ OMC $\times$ C & 0.02 & 0.03 & 0.8 & $-.04, .08$ \\
& & & & \\
Voluntary prayer $($ Panel B) & $\mathrm{b}$ & $\mathrm{SE}$ & $\mathrm{t}$ & $\mathrm{CIs}$ \\
\hline Constant & $3.89 * * *$ & 0.08 & 51.63 & $3.74,4.03$ \\
Condition $(\mathrm{C})$ & -.07 & 0.08 & -.96 & $-.22, .08$ \\
Ideology & -0.03 & 0.05 & -0.63 & $-.12, .06$ \\
OMC & 0.11 & 0.08 & 1.39 & $-.05, .27$ \\
Ideology $\times$ C & $-.29 * * *$ & 0.05 & -6.12 & $-.39,-.20$ \\
Ideology $\times$ OMC & -.02 & 0.04 & -.36 & $-.10, .07$ \\
OMC $\times$ C & .15 & 0.08 & 1.86 & $-.01, .31$ \\
Ideology $\times$ OMC $\times$ C & .05 & 0.04 & 1.20 & $-.03, .13$ \\
\hline
\end{tabular}

$* * * p<.001$

Notes: For the peaceful protest condition variable, $-1=$ prochoice, 1 = prolife. For the voluntary prayer condition variable, -1 = Muslim, 1 = Christian. 
Table 3

Study 2b: Moderated multiple regression analyses on scenario judgments

\begin{tabular}{|c|c|c|c|c|}
\hline Peaceful protest (Panel A) & $b$ & $S E$ & $t$ & CIs \\
\hline Constant & $2.21 * * *$ & 0.05 & 42.05 & $2.10,2.31$ \\
\hline Condition (C) & .05 & 0.05 & 0.99 & $-.05, .16$ \\
\hline Ideology & $.08^{*}$ & 0.03 & 2.42 & $.02, .14$ \\
\hline OMC & $-.28 * * *$ & 0.05 & -5.54 & $-.38,-.18$ \\
\hline Ideology $\times$ C & $-.14^{* * *}$ & 0.03 & -4.12 & $-.20,-.07$ \\
\hline Ideology $\times$ OMC & 0.04 & 0.03 & 1.32 & $-.02, .10$ \\
\hline $\mathrm{OMC} \times \mathrm{C}$ & -0.07 & 0.05 & -1.43 & $-.07, .03$ \\
\hline Ideology $\times$ OMC $\times \mathrm{C}$ & -0.04 & 0.03 & -1.48 & $-.10, .01$ \\
\hline Voluntary prayer (Panel B) & $b$ & $S E$ & $t$ & CIs \\
\hline Constant & $3.76^{* * *}$ & 0.07 & 50.23 & $3.61,3.91$ \\
\hline Condition (C) & .05 & 0.07 & .69 & $-.10, .20$ \\
\hline Ideology & 0.03 & 0.05 & 0.61 & $.12,-.06$ \\
\hline OMC & 0.03 & 0.07 & 0.40 & $-.11, .17$ \\
\hline Ideology $\times$ C & $-.34 * * *$ & 0.05 & -7.46 & $-.43,-.25$ \\
\hline Ideology $\times$ OMC & 0.01 & 0.04 & 0.26 & $-.06, .08$ \\
\hline $\mathrm{OMC} \times \mathrm{C}$ & 0.05 & 0.07 & 0.59 & $-.10, .18$ \\
\hline Ideology $\times$ OMC $\times \mathrm{C}$ & -0.05 & 0.04 & -1.24 & $-.12, .03$ \\
\hline College admissions (Panel C) & $b$ & $S E$ & $t$ & CIs \\
\hline Constant & $3.25 * * *$ & 0.07 & 46.97 & $3.11,3.39$ \\
\hline Condition (C) & -.01 & 0.04 & -.21 & $-.15, .12$ \\
\hline Ideology & $-.11 * *$ & 0.04 & -2.69 & $-.20,-.03$ \\
\hline OMC & -0.01 & 0.07 & -0.17 & $-.15, .13$ \\
\hline Ideology $\times$ C & $-.28 * * *$ & 0.04 & -6.73 & $-.37,-.20$ \\
\hline Ideology $\times$ OMC & -0.02 & 0.04 & -0.59 & $-.11, .06$ \\
\hline $\mathrm{OMC} \times \mathrm{C}$ & -.11 & 0.07 & -1.62 & $-.25, .02$ \\
\hline Ideology $\times$ OMC $\times \mathrm{C}$ & -0.03 & 0.04 & -0.73 & $-.12, .05$ \\
\hline Military officer (Panel D) & $b$ & $S E$ & $t$ & CIs \\
\hline Constant & $3.02 * * *$ & 0.06 & 47.12 & $2.89,3.14$ \\
\hline Condition (C) & $.25 * * *$ & 0.06 & 3.93 & $.13, .38$ \\
\hline Ideology & $.12 * *$ & 0.04 & 2.93 & $.04, .21$ \\
\hline OMC & $-.16^{* *}$ & 0.06 & -2.67 & $-.29,-.04$ \\
\hline Ideology $\times$ C & $-.21 * * *$ & 0.04 & -4.98 & $-.29,-.13$ \\
\hline Ideology $\times$ OMC & -0.02 & 0.04 & -0.70 & $-.09, .04$ \\
\hline $\mathrm{OMC} \times \mathrm{C}$ & 0.01 & 0.06 & 0.17 & $-.11, .13$ \\
\hline
\end{tabular}


\begin{tabular}{lllll} 
Ideology $\times$ OMC $\times$ C & 0.001 & 0.03 & 0.02 & $-.07, .07$ \\
\hline
\end{tabular}

$* * * p<.001$

Notes: For the peaceful protest condition variable, -1 = prochoice, 1 = prolife. For the voluntary prayer condition variable, $-1=$ Muslim, $1=$ Christian. For the college admissions condition variable, -1 = legacy-based, 1 = race-based. for the military office condition variable, $-1=$ Trump critic, 1 = Obama critic. 


\section{Table 4}

Study 3: Moderated multiple regression for biased assimilation on skepticism on gun rights article

\begin{tabular}{lcccc}
\hline & $b$ & $S E$ & $t$ & CIs \\
\hline Constant & $.51^{* * *}$ & 0.01 & 43.99 & $.48, .53$ \\
Condition (C) & $0.04^{* *}$ & 0.01 & 3.29 & $.02, .06$ \\
Gun support & -0.01 & 0.01 & -1.18 & $-.02, .005$ \\
OMC & -0.01 & 0.01 & -1.55 & $-.04, .01$ \\
Gun support $\times$ C & $-.05^{* * *}$ & 0.01 & -8.40 & $-.06,-.04$ \\
Gun support $\times$ OMC & 0.01 & 0.01 & 1.51 & $-.003, .02$ \\
OMC $\times$ C & 0.002 & 0.01 & 0.16 & $-.02, .03$ \\
Gun support $\times$ OMC $\times$ C & 0.002 & 0.01 & 0.29 & $-.01, .01$ \\
\hline
\end{tabular}

$* * * p<.001$

Notes: For the condition variable, -1 = gun rights; 1 = gun control. 
Figure 1

Study $1 a$ (top panel) and $1 b$ (bottom panel): Perceiver ideology $x$ target ideology $x$ OMC interactions
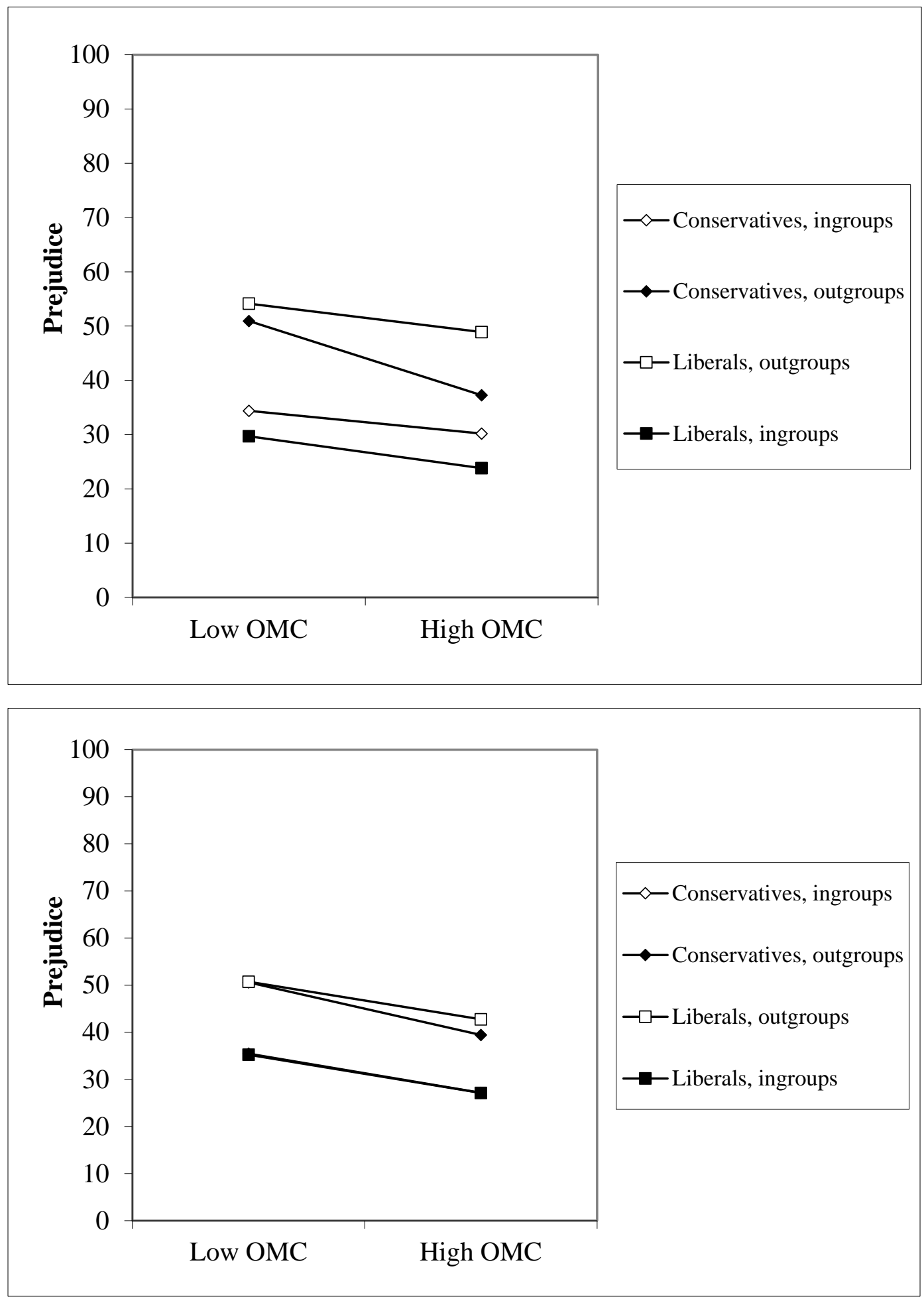

Notes 